\title{
Observation of sea-ice thickness fluctuation in the seasonal ice-covered area during 1992-99 winters
}

\author{
Kazutaka Tateyama, ${ }^{1,2}$ Hiroyuki Enomoto ${ }^{1,3}$ \\ ${ }^{1}$ Department of Civil Engineering, Kitami Institute of Technology, Koen-cho 165, Kitami 090-8507, Japan \\ ${ }^{2}$ Okhotsk Sea Ice Science Research Co., Ltd, 25-2, Moto-Mombetsu, Mombetsu 094-0023, Japan \\ ${ }^{3}$ Frontier Observational Research System for Global Change, SEAVANS N7, 1-2-1 Sibaura, Minatoku, Tokyo 105-0013, Japan
}

\begin{abstract}
Sea-ice fluctuations in the Sea of Okhotsk and the Bering Sea during the winters of 1992-99 were investigated by using the Special Sensor Microwave/ Imager dataset and a new ice-property retrieval algorithm. This algorithm can distinguish between ice types such as fast ice, floes, young ice and new ice, in an area covered by concentrations of $>80 \%$ ice, and also has improved display resolution because it uses one of the $85 \mathrm{GHz}$ channels. The ice thicknesses derived from the ice-thickness parameter of the new algorithm were compared with ship-based ice-thickness measurements, and were assumed to be $1-10,11-34,35-85$ and $86-120 \mathrm{~cm}$ for new ice, young ice, floes (first-year ice) and fast ice, respectively. The results showed that ice volume can be small even if the ice area is large, due to thinness of the ice (e.g. in 1999 in the Sea of Okhotsk). A significant out-of-phase response, i.e. ice volume is larger in the Sea of Okhotsk when ice volume is smaller in the Bering Sea, was observed. The period of this see-saw showed two different time-scales, which were short (1 week) and long (2-4 weeks).
\end{abstract}

\section{INTRODUGTION}

Observations by the Special Sensor Microwave/Imager $(\mathrm{SSM} / \mathrm{I})$, which is part of the operational United States Defense Meteorological Satellite Program (DMSP) and first flew in 1987, have shown fluctuations of ice concentration and extent in the Sea of Okhotsk (Enomoto, 1996; Nishio and Cho, 1996), and a rapid decrease of ice extent since 1989 (Tachibana and others, 1996). Parkinson and others (1999) used the combined ice-cover record that had been produced by the Scanning Multi-channel Microwave Radiometer (SMMR) on board the Nimbus 7 satellite and the $\mathrm{SSM} / \mathrm{I}$ to show the decreasing trend of ice-covered areas in the Sea of Okhotsk and the increasing yearly average icecovered area in the Bering Sea since 1978.

Cavalieri (1994) presented a technique for mapping the distribution of new, young and first-year ice in the Bering Sea from SSM/I data. This technique used a polarization ratio (PR) from the 19 and $37 \mathrm{GHz}$ channels to classify ice types. The PR is sensitive to changes in ice. This technique has solved the problem of thin-ice signals being regarded as multi-year ice in the Bering Sea and the Sea of Okhotsk, but still involves problems of low resolution in local areas and confusion of concentrations in areas of mixed ice types.

The $85 \mathrm{GHz}$ channels of SSM/I have a sampling resolution of $12.5 \times 12.5 \mathrm{~km}^{2}$, twice that of the other channels. However, sea-ice algorithms based on the 19, 22 and $37 \mathrm{GHz}$ channels were used to calculate ice concentration, due to weather contamination in the $85 \mathrm{GHz}$ channels. Sea-ice classification experiments have been performed by airborne sensors and in laboratories that have also used higher-frequency channels (Troy and others, 1981; Eppler and others, 1992; Wensnahan and others, 1993). These experi- ments showed that it is possible to distinguish between ice types by combining higher-frequency channels, i.e. the $85 \mathrm{GHz}$ of SSM/I, with other channels.

The objective of this study was to estimate ice thicknesses and ice volumes in the seasonal ice-covered areas, such as the Sea of Okhotsk and the Bering Sea (see Fig. 1). These regions are expected to be greatly affected by climate change. The relative thinness of sea ice in these two seas makes the ice cover sensitive to being eliminated by small or slight changes in climate and ocean temperature. The study was carried out using the SSM/I dataset with a new algorithm, S/KIT (Tateyama and others, 2000). This algorithm can distinguish between ice types such as fast ice, floes, young ice, new ice and multi-year ice in areas with $>80 \%$ ice concentrations and has a fine spatial resolution $\left(12.5 \times 12.5 \mathrm{~km}^{2}\right)$ within ice-covered regions.

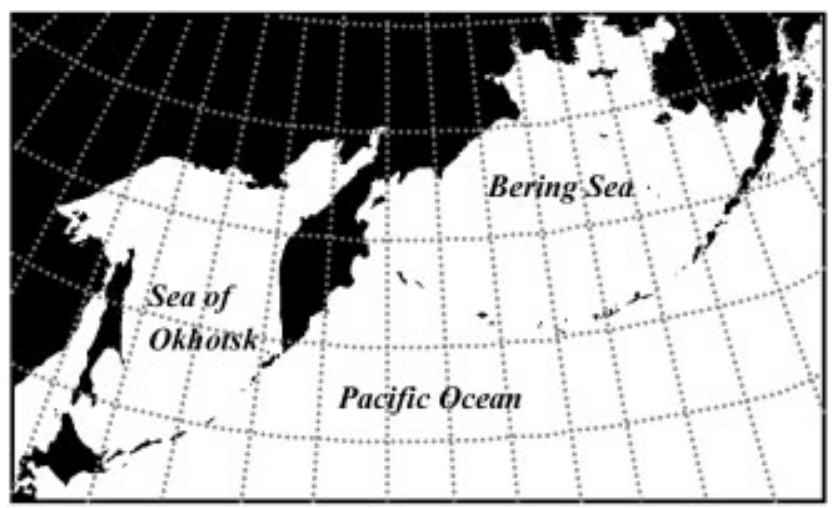

Fig. 1. Location map of the Sea of Okhotsk and adjacent regions including the Japan Sea, Pacific Ocean and Bering Sea. 

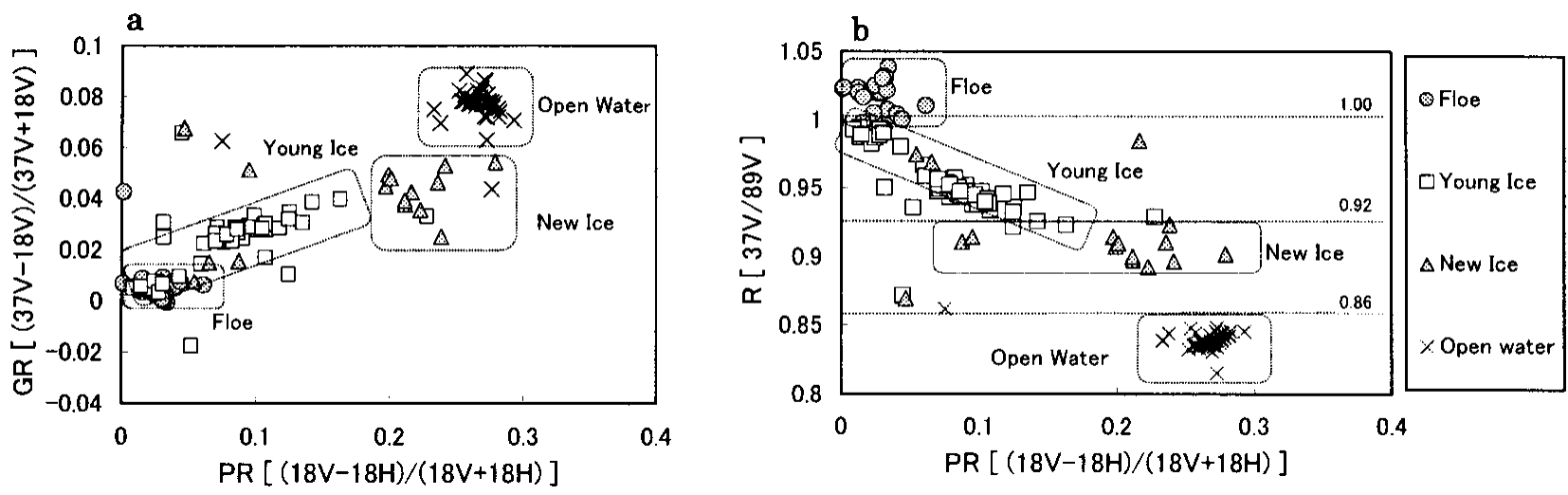

Fig. 2. Ice-signal distribution, taken by AMR on 17 February 1996 in the Sea of Okhotsk. (a) The NASA Team algorithm (PRGR plane); (b) $P R-R_{37 \mathrm{~V} / 89 \mathrm{~V} \text { plane. }}$

\section{ICE-CONCENTRATION DATA}

The daily brightness temperatures were derived from the $\mathrm{SSM} / \mathrm{I}$, which has vertically and horizontally polarized 19,37 and $85 \mathrm{GHz}$ channels and a vertically polarized $22 \mathrm{GHz}$ channel. The $85 \mathrm{GHz}$ channel has a sampling resolution twice as high as that of the other channels because it is sampled twice as often (Hollinger and others, 1989). These data are distributed by the U.S. National Snow and Ice Data Center (NSIDG) in Boulder, CO. From the brightness temperatures of these channels, ice concentrations were calculated with the modified NASA Team "thin-ice" algorithm (Cavalieri, 1994) with a gridcell size of $25 \times 25 \mathrm{~km}^{2}$, using the tie points for the Sea of Okhotsk that were developed by Enomoto (1996). For the Bering Sea, Cavalieri's tie points were used (personal communication from D. J. Cavalieri, 1999).

\section{S/KIT ALGORITHM}

\subsection{Development of the algorithm}

In winter 1996, a field sea-ice observation experiment, the Sea Ice Observation Program for the Sea of Okhotsk (SIPSO), was carried out. This experiment used a National Space Development Agency of Japan (NASDA)-developed Airborne Microwave Radiometer (AMR) mounted on a Beachcraft-200 airplane (B-200) to collect surface measurements in Lake Saroma, northern Hokkaido, Japan, and the Sea of Okhotsk. The AMR has 6.925, 10.65, 18.7, 23.8, 36.5 and $89.0 \mathrm{GHz}$ channels, each of which can measure vertical and horizontal polarization. This instrument was developed for a ground experiment related to the Advanced Microwave Scanning Radiometer (AMSR) on the NASDA ADEOS-II satellite, which will be launched in 2001. A videotape recorder (VTR) camera and an infrared radiometer were also mounted on the airplane.

Lake Saroma is a $150.4 \mathrm{~km}^{2}$ salt lagoon connected to the Sea of Okhotsk by two estuaries, and freezes up entirely with about $30 \mathrm{~cm}$ thick ice. Tateyama and others (2000) described the development of a new algorithm based on the SIPSO experiment, the SIPSO/Kitami Institute of Technology (S/KIT) algorithm. TheVTR images were taken by the B-200 and used as the distribution data for the ice-surface conditions. From theVTR images the ice-thickness distribution was estimated by observing the surface color, size, snow cover and edge ridging.
The distribution of the brightness temperature $\left(T_{\mathrm{B}}\right)$ of the vertically polarized $89.0 \mathrm{GHz}$ channel $\left(T_{\mathrm{B} 89 \mathrm{~V}}\right)$ of the AMR varied with ice thickness and the ice surface. This variation was from about $235 \mathrm{~K}$ on snow-covered thick ice to about $270 \mathrm{~K}$ on the bare thin ice. In contrast, the $T_{\mathrm{B}}$ from the vertically polarized $36.5 \mathrm{GHz}$ channel $\left(T_{\mathrm{B} 37 \mathrm{~V}}\right)$ was $250-$ $265 \mathrm{~K} . T_{\mathrm{B} 89 \mathrm{~V}}$ shows similar results to the infrared measure of surface ice temperature. $T_{\mathrm{B} 37 \mathrm{~V}}$ comes from about $3 \mathrm{~cm}$ depth and shows a constant value compared to $T_{\mathrm{B} 89 \mathrm{~V}}$. $T_{\mathrm{B} 89 \mathrm{~V}}$ cannot differentiate between open water and ice, as it indicates almost the same brightness temperature because the emissivity of open water rises with frequency. Hence, the contrast between sea ice and open water in the $85 \mathrm{GHz}$ channel is too small to differentiate them. To obtain higher spatial resolution, to discriminate among ice types according to thickness and to detect open water, a designated ratio between

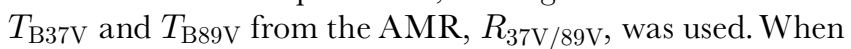
the $R_{37 \mathrm{~V} / 89 \mathrm{~V}}$ is low in the packed-ice area, the temperature of ice in the upper layer is assumed to be low, meaning that the ice is thick, and vice versa. Although $T_{\mathrm{B} 89 \mathrm{~V}}$ cannot detect

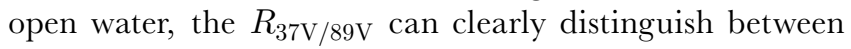
open water and ice by using $T_{\mathrm{B} 37 \mathrm{~V}}$, which is sensitive to the different dielectric constant between the ice and water. This difference between $T_{\mathrm{B} 37 \mathrm{~V}}$ and $T_{\mathrm{B} 89 \mathrm{~V}}$ in open water is larger than that obtained using $T_{\mathrm{B} 37 \mathrm{~V}}$ or any other single channel, so the $R_{37 \mathrm{~V} / 89 \mathrm{~V}}$ is better at finding open water.

\subsection{Ice-classification ability}

Figure 2 shows the results of ice classification using AMR observations for the area covered by new ice, young ice and floe, off the eastern coast of Hokkaido. Figure 2a uses the NASA Team algorithm PR-GR plane (Cavalieri and others, 1991); Figure $2 \mathrm{~b}$ uses $R_{37 \mathrm{~V} / 89 \mathrm{~V}}$ instead of GR. PR and $\mathrm{GR}$ are given by

$$
\begin{aligned}
& \mathrm{PR}=\left(T_{\mathrm{B} 19 \mathrm{~V}}-T_{\mathrm{B} 19 \mathrm{H}}\right) /\left(T_{\mathrm{B} 19 \mathrm{~V}}+T_{\mathrm{B} 19 \mathrm{H}}\right) \\
& \mathrm{GR}=\left(T_{\mathrm{B} 37 \mathrm{~V}}-T_{\mathrm{B} 19 \mathrm{~V}}\right) /\left(T_{\mathrm{B} 37 \mathrm{~V}}+T_{\mathrm{B} 19 \mathrm{~V}}\right) .
\end{aligned}
$$

PR is not only a good water/ice discriminator, but is also largely independent of the physical temperature from the radiating medium since it is the ratio of the observed radiance. GR is defined as a discriminator of ice type by using the differences of slope between the $T_{\mathrm{B}}$ at 36.5 and $18.7 \mathrm{GHz}$. PR mainly gives ice concentrations. GR gives a fraction between the two ice types, which are first-year ice and multiyear ice in the Arctic. In the Antarctic, this fraction consists of first-year ice and heavy snow-covered ice (Cavalieri and 
$\mathbf{a}$

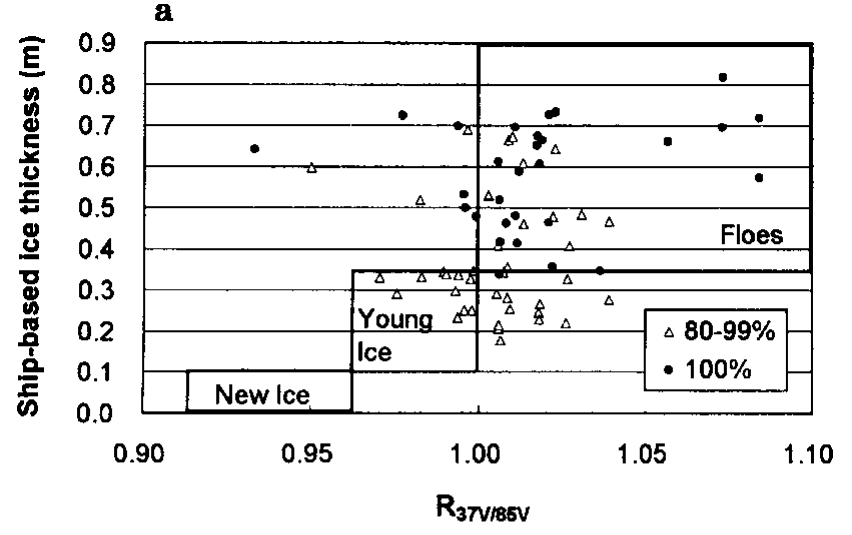

b

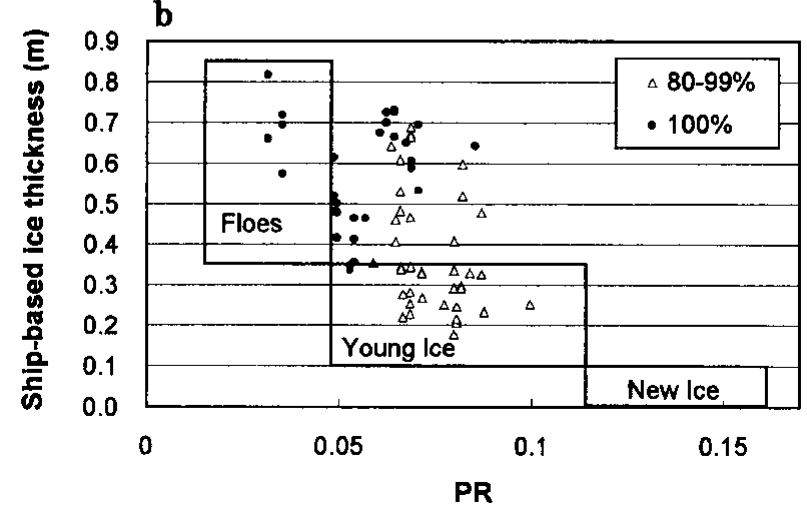

Fig. 3. The ship-based ice thickness vs thickness parameters.

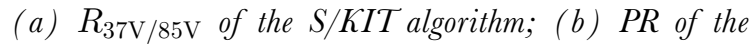
MNTalgorithm.

others, 1984; Markus and Cavalieri, 1998). The NASA Team algorithm in the PR-GR plane is represented by a curvilinear triangle whose vertices are defined by tie points, which consist of the $T_{\mathrm{B}}$ values for open water, first-year ice and new ice (Cavalieri, 1994).

The results show that it is hard to distinguish young ice from floes by using the PR-GR plane (Fig. 2a). When $R_{37 \mathrm{~V} / 89 \mathrm{~V}}$ is used instead of GR, discrimination between ice floes and young ice is possible by using the $R_{37 \mathrm{~V} / 89 \mathrm{~V}}=1.00$ line (Fig. 2b). Young ice and newly formed ice can be divided by $R_{37 \mathrm{~V} / 89 \mathrm{~V}}=0.92$, and new ice and open water can be divided by $R_{37 \mathrm{~V} / 89 \mathrm{~V}}=0.86$. The new ice, young ice and floes have respective thicknesses of $<10,10-40$ and $>40 \mathrm{~cm}$.

\subsection{Comparison with ship-based measurements}

Ice and oceanographic observations were carried out by the Institute of Low Temperature Science, Hokkaido University, and the Ship Research Institute, Ministry of Transport, using the Japanese Coast Guard ice-breaker Soya off the eastern coast of Hokkaido in February 1996 and 1997 (Toyota and others, 1999). Albedo, ice concentrations, ice thicknesses and snow depths were estimated by video analysis. The ice-

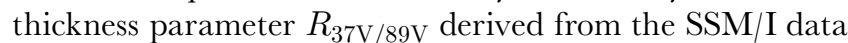
with the $\mathrm{S} / \mathrm{KIT}$ algorithm was validated using the ship-based ice-measurement data. Figure 3 a shows the relationship between the ship-based measurements and $R_{37 \mathrm{~V} / 89 \mathrm{~V} \text {. The }}$

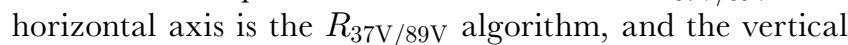
axis is the ship-based ice measurements. The ship data were converted to the stereographic grids for SSM/I, and averaged about 62 samples for every one of the gridcells. The histogram for ice depths derived from the ship's observations ranged from 18 to $82 \mathrm{~cm}$, the most frequent range being 60
$70 \mathrm{~cm}$ thick and the second most frequent $30-40 \mathrm{~cm}$ thick. There were no samples of new ice $1-10 \mathrm{~cm}$ thick from these ship data. For the thinner-ice validation, AMR experimental data and satellite images were used (Tateyama and others, 2000). The results are indicated by the solid box in Figure 3.

The effect of snow cover over sea ice on the estimation of ice thickness cannot be neglected, because the $85 \mathrm{GHz}$ channel is sensitive to surface changes. From ship observations the snow cover normally does not exceed $20 \%$ of ice thickness in large ice-drifting regions. On the thin ice, snow will be blown away by wind or melted by surface brine. The snow cover was taken into account in an emphasis factor of ice thickness in this study. In other words, snow cover is deep when ice is thick, and vice versa.

Scatter plots are shown in Figure 3. Black dots and gray triangles indicate $100 \%$ and $80-99 \%$ packed-ice samples in a concentration calculated by the tie-points modified NASA Team thin-ice (MNT) algorithm for the Sea of Okhotsk (Enomoto, 1996). The areas surrounded by boxes indicate ice-type classification from the S/KIT algorithm. From this result, ice classifications were summarized so that floe ice, which ranged from 35 to $85 \mathrm{~cm}$ in the ship-based ice measurement, was classified between 1.00 and 1.10 in the $R_{37 \mathrm{~V} / 89 \mathrm{~V}}$ algorithm. Young ice $11-35 \mathrm{~cm}$ thick was scattering in $0.97-0.99$. Ice $30-40 \mathrm{~cm}$ thick tended to indicate concentrations of $80-99 \%$.

Figure $3 \mathrm{~b}$ shows the relationship between the ship-based measurements and the PR. Ice types were categorized for PR ranges of $0.12-0.17,0.05-0.12$ and $0.02-0.05$ for new ice, young ice and thick first-year ice, respectively (Cavalieri, 1994). The PR variation tends to classify the thin-ice type as "loose packed ice". The ice classifications for $100 \%$ concentration were improved by using the thickness parameter $R_{37 \mathrm{~V} / 89 \mathrm{~V}}$, although there were a few mis-categorized points.

For application of the S/KITalgorithm to the SSM/I datasets over the whole Sea of Okhotsk, visible and near-infrared images from the Advanced Very High Resolution Radiometer (AVHRR) on board the U.S. National Oceanic and Atmospheric Administration (NOAA) satellite and Advanced Visible and Near Infrared Radiometer (AVNIR) images from the Advanced Earth Observation System (ADEOS) satellite were used for tuning the threshold values of ice types (Table 1). The S/KIT algorithm has a higher resolution of $12.5 \times 12.5$ $\mathrm{km}^{2}$, and the data contamination caused by "weather and land effects" was reduced as described in the next subsection.

\subsection{Weather and land effects}

It is necessary to remove contamination from the microwave

Table 1. Threshold values of $R_{37 \mathrm{~V} / 85 \mathrm{~V}}$ for four ice types, lower concentration area than $80 \%$ and open water

\begin{tabular}{|c|c|c|}
\hline Category & $\begin{array}{c}\text { Thickness } \\
\mathrm{cm}\end{array}$ & Threshold values \\
\hline Fast ice & $86-120$ & $1.12 \leq R_{37 \mathrm{~V} / 85 \mathrm{~V}}$ \\
\hline Floes & $35-85$ & $1.00 \leq R_{37 \mathrm{~V} / 85 \mathrm{~V}}<1.12$ \\
\hline Young ice & $11-34$ & $0.97 \leq R_{37 \mathrm{~V} / 85 \mathrm{~V}}<1.00$ \\
\hline New ice & $1-10$ & $\begin{array}{l}0.92 \leq R_{37 \mathrm{~V} / 85 \mathrm{~V}}<1.00 \text { and } \\
0.70 \leq R_{19 \mathrm{H} / 85 \mathrm{~V}}<0.80\end{array}$ \\
\hline $\begin{array}{l}\text { Low concentration } \\
\text { Open water }\end{array}$ & $1-50$ & $\begin{aligned} 0.92 \leq & R_{37 \mathrm{~V} / 85 \mathrm{~V}}<0.97 \\
R_{37 \mathrm{~V} / 85 \mathrm{~V}} & <0.92\end{aligned}$ \\
\hline
\end{tabular}




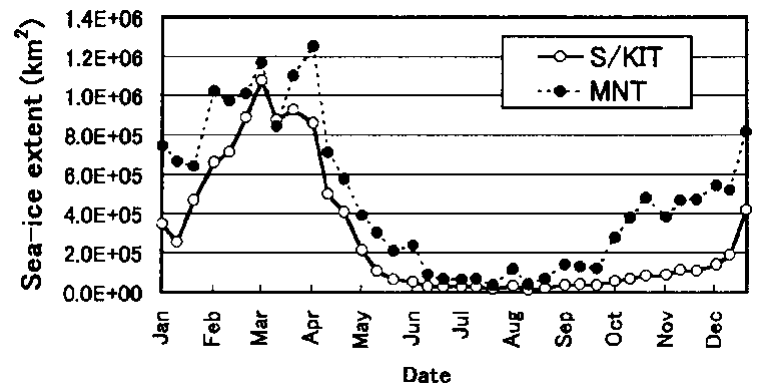

Fig. 4. A time series of sea-ice extent in the Sea of Okhotsk during 1 January-31 December 1996 (10 days interval). The solid line showes the S/KIT algorithm, and the dashed line shows the MNTalgorithm.
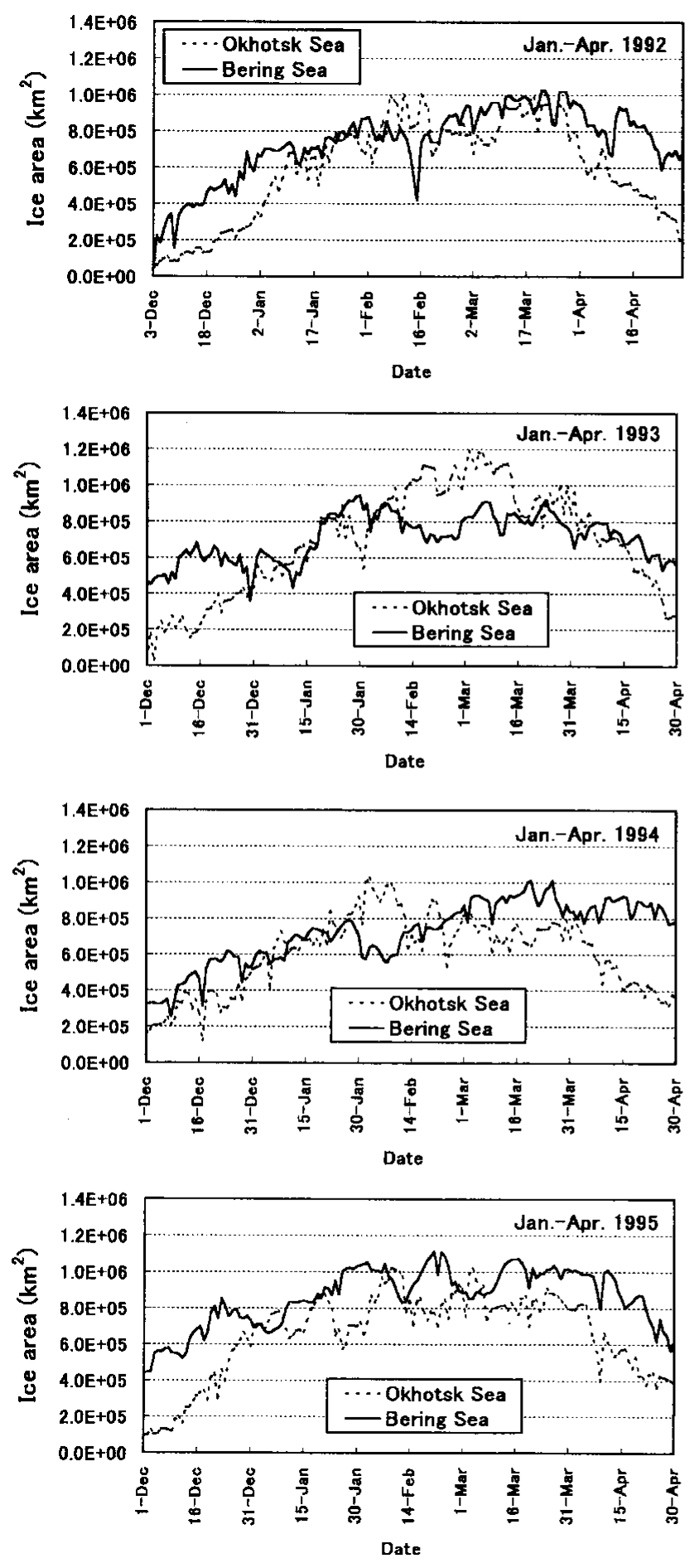

Table 2. Summary of ice-area, thickness and volume variations in the Sea of Okhotsk and the Bering Sea, December 1991-March 1999

\begin{tabular}{|c|c|c|c|c|c|c|}
\hline & \multicolumn{3}{|c|}{ Sea of Okhotsk } & \multicolumn{3}{|c|}{ Bering Sea } \\
\hline & Area & Thickness & Volume & Area & Thickness & Volume \\
\hline & $10^{5} \mathrm{~km}^{2}$ & $\mathrm{~m}$ & $10^{2} \mathrm{~km}^{3}$ & $10^{5} \mathrm{~km}^{2}$ & $\mathrm{~m}$ & $10^{2} \mathrm{~km}^{3}$ \\
\hline Mean & 6.0 & 0.28 & 1.9 & 7.3 & 0.41 & 3.1 \\
\hline \multicolumn{7}{|c|}{ Maximum } \\
\hline lst year & $7.0(1998)$ & 0.32 & 2.3 & $8.6(1995)$ & 0.45 (1995) & $4.0(1995)$ \\
\hline 2nd year & 6.9 (1993) & $(1993,1995)$ & $(1993,1995)$ & $7.8(1998)$ & 0.44 (1997) & $3.2(1997)$ \\
\hline \multicolumn{7}{|c|}{ Minimum } \\
\hline lst year & $4.4(1996)$ & $0.22(1996)$ & 1.2 & $5.9(1996)$ & $0.37(1998)$ & $2.5(1996)$ \\
\hline 2nd year & $4.8(1997)$ & $0.23(1997)$ & $(1996,1997)$ & $7.0(1997)$ & $0.39(1992)$ & $3.0(1992)$ \\
\hline
\end{tabular}
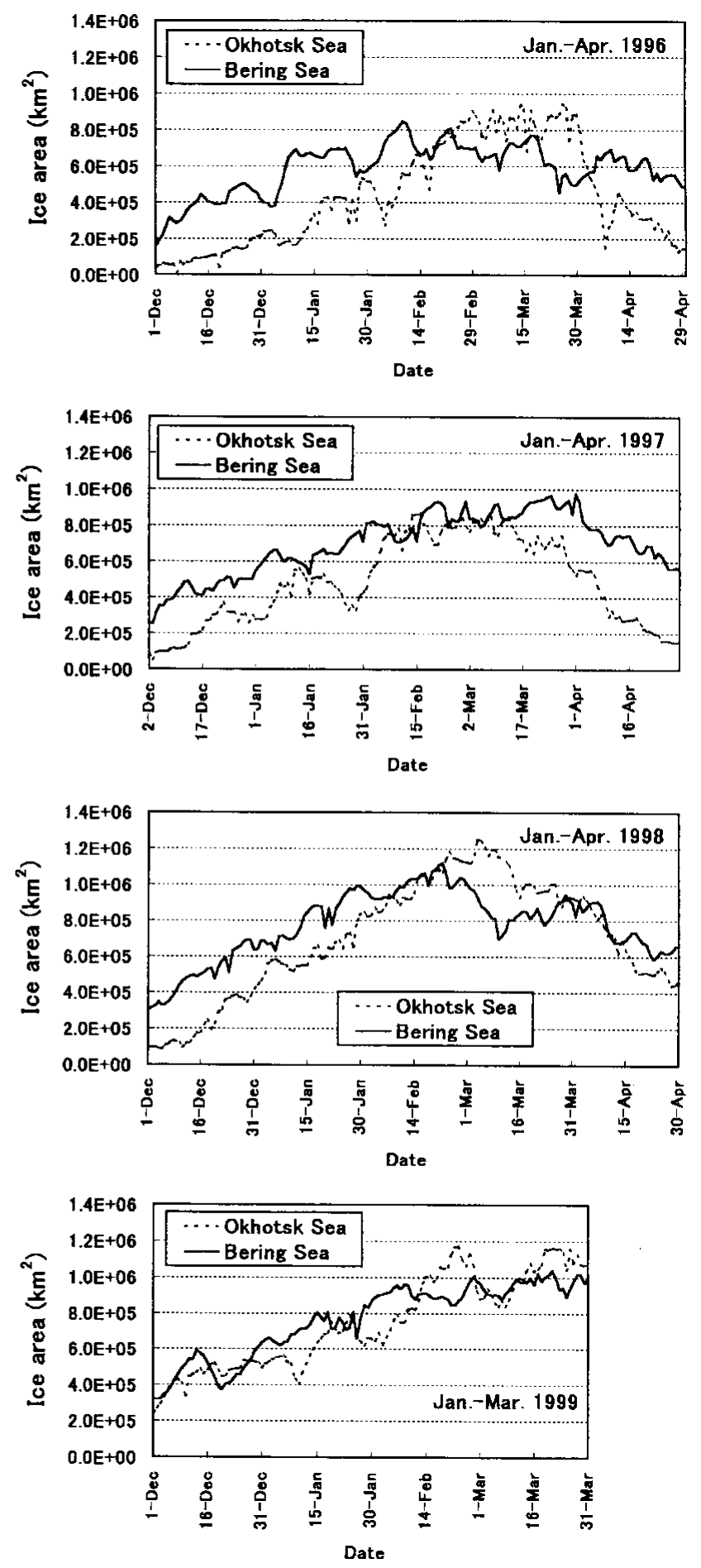

Fig. 5. Daily sea-ice area during 1992-99 winters (December-April) in the Sea of Okhotsk and the Bering Sea. 

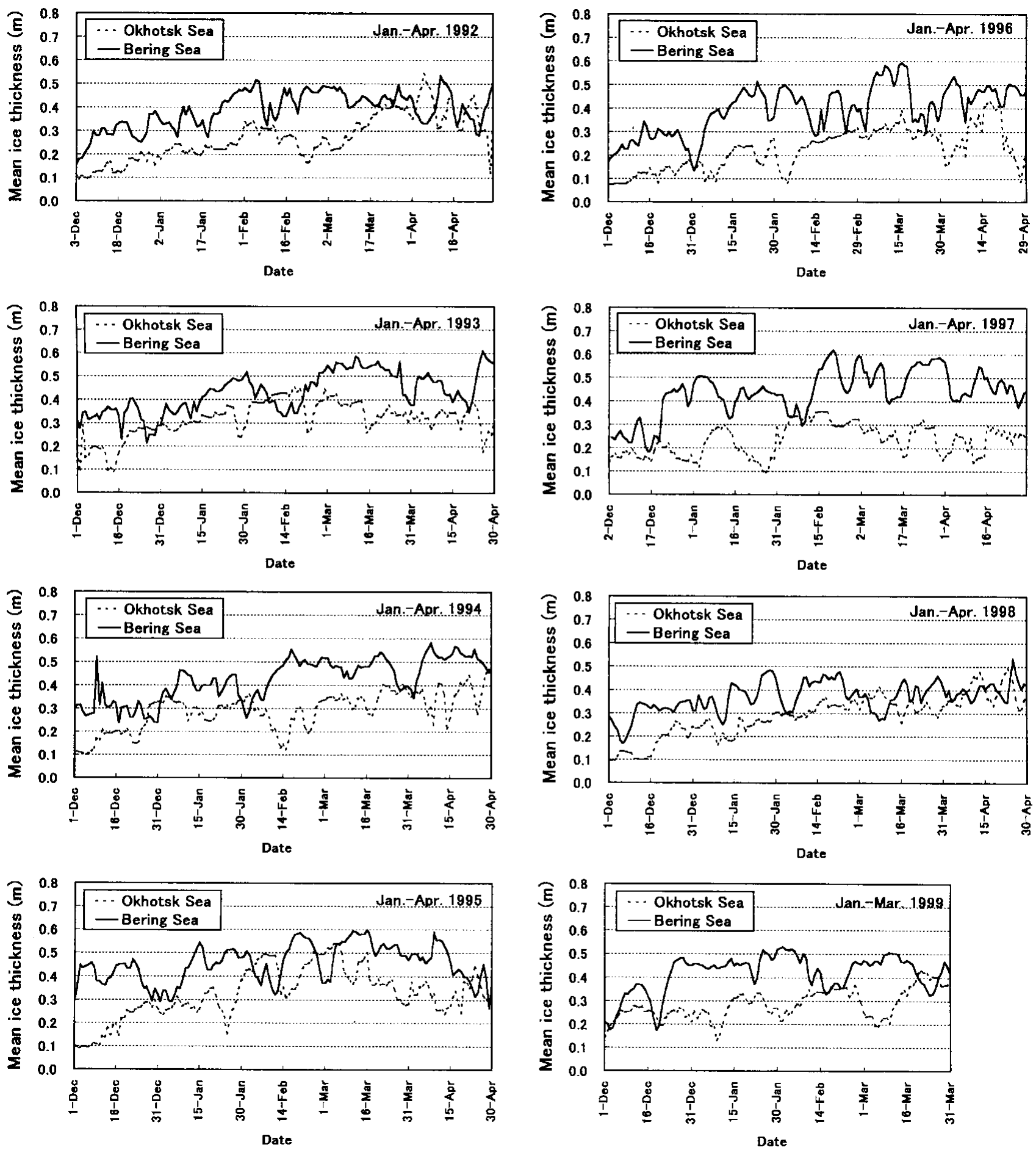

Fig. 6. Daily spatial mean sea-ice thickness during 1992-99 winters (December-April) in the Sea of Okhotsk and the Bering Sea.

ice signals. This contamination of the microwave sea-ice signal is due to water vapor, clouds, rainfall and snowfall. A "land-proximity effect" also causes a false ice signal because of the side lobe of the antenna pattern when a field of view includes land. This has a serious effect on observations of the coastal sea-ice distribution. Although it is possible to remove the atmospheric-signal contamination by using weather filters, it is impossible to separate the land contamination from the ice signal merely by means of an algorithm, because of the side lobe and its spatial resolution. However, the area affected by land noise can be reduced by increasing the resolution.

This study uses a weather filter suggested byJ. C. Comiso (personal communication, 1994), but with a slightly lower value in the following threshold. The concentration is to be set at $0 \%$ when

$$
T_{\mathrm{B} 22 \mathrm{~V}}-T_{\mathrm{B} 19 \mathrm{~V}}>12 .
$$

The weather filter for the Sea of Okhotsk, suggested by Cho and others (1996), is also used. If GR >0.05 and $\mathrm{GR}^{\prime}>0.03$, where $\mathrm{GR}^{\prime}$ is given by

$$
\mathrm{GR}^{\prime}=\left(T_{\mathrm{B} 22 \mathrm{~V}}-T_{\mathrm{B} 19 \mathrm{~V}}\right) /\left(T_{\mathrm{B} 22 \mathrm{~V}}+T_{\mathrm{B} 19 \mathrm{~V}}\right),
$$

then this concentration is substituted for $0 \%$. The $T_{\mathrm{B}}$ of the vertically polarized $22 \mathrm{GHz}\left(T_{\mathrm{B} 22 \mathrm{~V}}\right)$ channel is used to measure atmospheric effects because this channel is located in an absorption band of the atmosphere. 

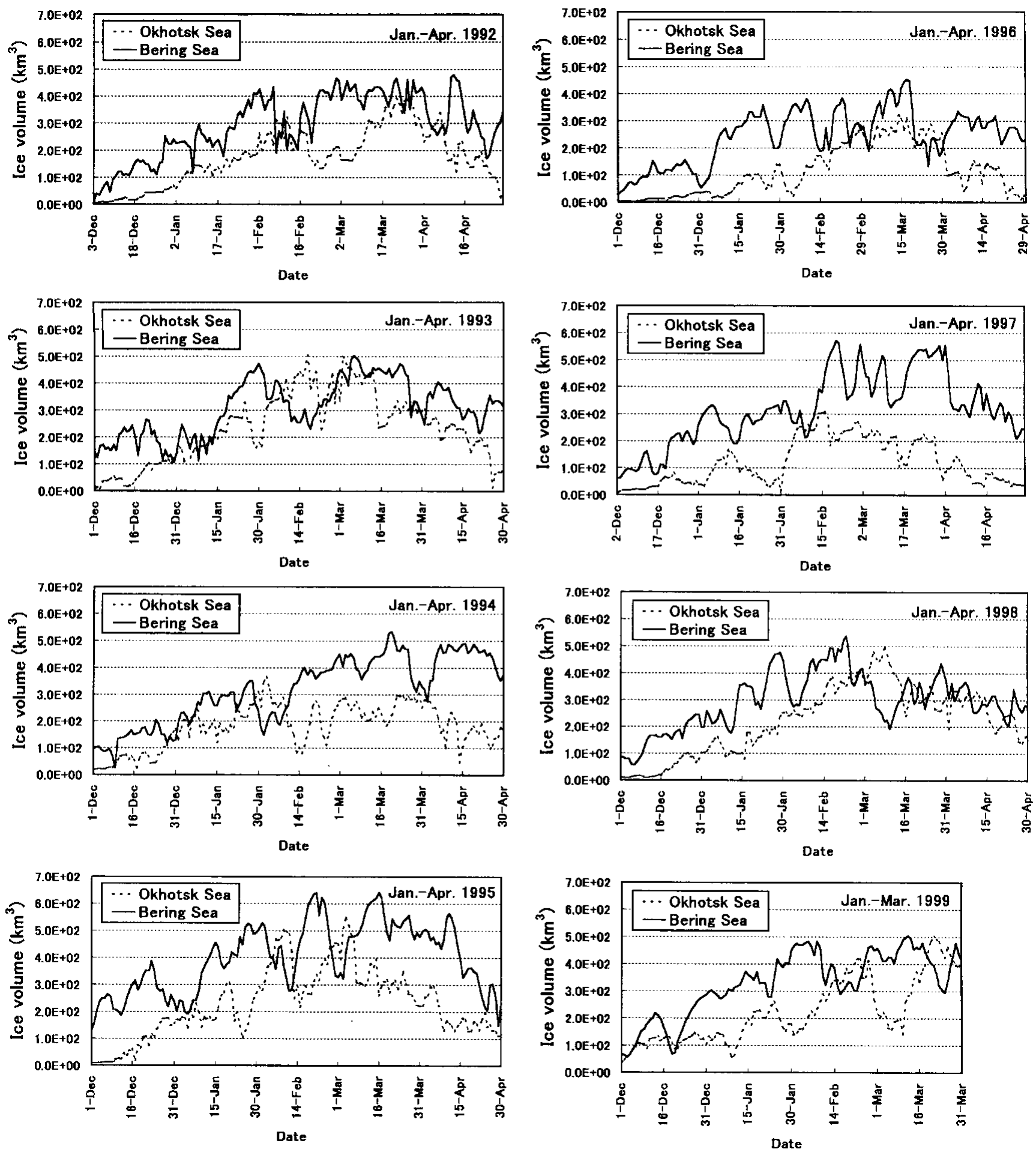

Fig. 7. Daily sea-ice volume during 1992-99 winters (December-April) in the Sea of Okhotsk and the Bering Sea.

A significant reduction in land contamination was obtained by increasing the resolution. Figure 4 compares the seasonal ice extent estimated by the MNT algorithm and the S/KIT algorithm for the Sea of Okhotsk during January-December 1996. Since there is no sea ice between June and the beginning of November, ice signals in this period are always false. The false ice signals from the MNT algorithm in the summer reach $10 \%$ of the average winter ice area, whereas the $\mathrm{S} / \mathrm{KIT}$ algorithm shows $<3 \%$ false signals. Especially in summer, the S/KITalgorithm has less false ice, with a mean value of $60 \%$ fewer and a maximum value of $80 \%$ fewer false signals than the MNT algorithm. Even in December and May, when there are false signals due to the land-proximity effect, the S/KIT algorithm reduces these by applying a higher-spatial-resolution channel, while confirming the ice signal with the pixels of the lower-spatial-resolution channel (i.e. $37 \mathrm{GHz}$ ) along the coast and ice edge.

These weather filters (Equations (3) and (4)) are not designed to differentiate between sea ice and weather contamination over sea ice. Therefore our ice products are assumed to be free of weather effects. Despite the absence of effective filters for weather contamination over sea ice, pending further study, the S/KIT-algorithm-derived data appear to be more reliable. A considerable number of ice maps were examined using the $\mathrm{S} /$ KIT algorithm comparing cloud-cover information derived from NOAA AVHRR satellite images, but there was little ap- 
parent weather effect over sea ice. Sea-ice-type signals were quite stable in the successive daily images, although skies were frequently overcast.

\section{TIME SERIES OF ICE-COVER FLUGTUATIONS}

\subsection{Calculation of ice thickness and ice volume}

The SSM/I data are available from 1987, but the $85 \mathrm{GHz}$ channels were too noisy to use between 1989 and 1991. Icethickness and -volume estimates using the S/KITalgorithm were carried out from December 1991.

Ice volume was calculated as the product of the ice thickness and ice-covered area, which has been defined as gridcells containing ice weighted by the ice concentration. Ice of several thicknesses was assumed from the parameter $R_{37 \mathrm{~V} / 85 \mathrm{~V}}$. This parameter varies with ice types as shown in Table 1. Fast ice, which appears to have a smooth surface and is a brighter white than ice floes in AVHRR images (e.g. around the estuary of the Amur River), was defined as 86$120 \mathrm{~cm}$ thick. Ice thickness $h(\mathrm{~cm})$ is calculated using the following equation:

$$
h=h_{0}+C\left(R_{37 \mathrm{~V} / 85 \mathrm{~V}}-\mathrm{TH}\right),
$$

where $h_{0}$ is the minimum thickness of each ice type. New ice, young ice, floes and fast ice have $h_{0}$ values of 1, 11, 35 and $86 \mathrm{~cm}$ thick, respectively. These minima are derived from ship-based measurements. $C$ is a constant that is calculated by the range in ice thicknesses divided by $R_{37 \mathrm{~V} / 85 \mathrm{~V}}$ (maximum) minus the threshold values TH of each of the ice types. TH is from the lower threshold value of $R_{37 \mathrm{~V} / 85 \mathrm{~V}}$ in Table 1 . In the case of floe ice, for example, $h_{0}, C$ and TH are $35,454.5$ and 1.00, respectively. For ice of low concentrations, thicknesses ranged from 1 to $50 \mathrm{~cm}$ because low concentrations of ice can always be seen in the marginal ice zone. In this area, sea ice consists of new ice and crushed ice, so ice thicknesss can generally be regarded as thin. The contribution of areas of low concentration to total ice-covered area is low in the maximum ice-covered season.

Total ice volume $V_{\text {total }}$ was calculated by

$$
V_{\text {total }}=\sum\left(A_{\text {local }} \times h_{\text {local }}\right) \text {, }
$$

where $A_{\text {local }}$ and $h_{\text {local }}$ are ice area and ice thickness, respectively, in each of the gridcells.

Spatial mean ice thickness is calculated by dividing daily total ice volume by daily ice area. This value indicates the average ice thickness over the whole study area.

\subsection{Time series of ice area, thickness and volume}

Table 2 shows the yearly mean ice area, thickness and volume as well as the maximum two and minimum two measures for this study period. Intra-seasonal fluctuations of ice area, thickness and volume are shown in Figures 5-7, respectively. These figures show the daily ice products given by the S/KITalgorithm over the study period.

In the Sea of Okhotsk the two years with the minimum yearly area average were 1996 and 1997, with 62.9\% and $68.6 \%$, respectively, of the maximum yearly area average (1998). In the Bering Sea the minimum winter average area was observed in 1996 and was $68.6 \%$ of the maximum winter average area (1995). Differences between the largest and smallest ice volume were more marked. In the Sea of Okhotsk the winter average volumes in 1996 and in 1997 were $52.2 \%$ of the maximum winter average volumes in
1993 and 1995. In the Bering Sea the ice volume for 1996 was the smallest and was $62.5 \%$ of the maximum in 1995 .

Except for 1995 and 1997 the daily ice areas of the Sea of Okhotsk were larger than those of the Bering Sea, but the winter average areas of the Sea of Okhotsk were always 10$30 \%$ smaller than those of the Bering Sea. Mean winter ice thicknesses in the Bering Sea were always thicker than in the Sea of Okhotsk. The winter average ice thickness during this period in the Sea of Okhotsk was $0.28 \mathrm{~m}$. In 1996 and 1997 the spatial mean ice thicknesses were thin, 0.22 and $0.23 \mathrm{~m}$, respectively. In 1998, although the winter average ice area was the largest for the period of study, the mean ice thickness was not thick, with the result that the winter average ice volume was not the largest. Likewise, in the Bering Sea, the winter average ice volume in 1998 was below average, although the ice area covered was the second largest, because the winter mean ice thickness was the thinnest. These results suggest that ice area and ice thickness do not vary together but can vary out of phase. One possible reason for this is that ice area is much affected by wind, while ice thickness is much affected by surface air temperature, but this must await further study.

The intra-winter variation was greater for ice thickness and volume than for variation in ice area. A negative correlation can be seen between these two seas. This out-of-phase "see-saw" response showed the two different time-scales, which are short (1 week) and long (2-4 weeks). The shorttime-scale variations, which look like negative and positive spikes, are thought to be caused by the movement of low-pressure weather systems. A low approaching the ice-covered area may make the ice area smaller and looser due to warmair advection (negative spike), and a departing low may make it larger due to cold-air advection (positive spike). Ice thickness clearly showed not only a short- but also a long-term variation, which may be caused by changes in the strength of the Aleutian low. The ice area and thickness is smaller and thinner in the Sea of Okhotsk when the Aleutian low strengthens (Tateyama and Enomoto, 2000).

\section{GONGLUDING REMARKS}

Ice thicknesses and volumes were estimated by using the thickness parameter $R_{37 \mathrm{~V} / 85 \mathrm{~V}}$, i.e. the ratio between $T_{\mathrm{B} 37 \mathrm{~V}}$ and $T_{\mathrm{B} 85 \mathrm{~V}}$ of the satellite microwave radiometer $\mathrm{SSM} / \mathrm{I}$. From ship-based ice-thickness measurements, $R_{37 \mathrm{~V} / 85 \mathrm{~V}}$ shows an improved ice-category coverage compared to the sea-ice analysis by $\mathrm{PR}-\mathrm{GR}$ plane. Ice thickness was assumed to be $1-10,11-34,35-85,86-120 \mathrm{~cm}$ for new ice,

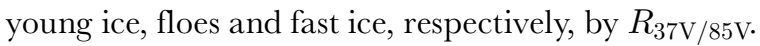

Ice volumes may be small even when ice areas are large because ice thicknesses may be thin, as in 1998 in the Sea of Okhotsk and the Bering Sea. This different phase variation could occur because ice area and thickness are much affected by wind and surface air temperature, respectively.

The out-of-phase response in the Sea of Okhotsk and the Bering Sea appeared in this period. This see-saw is more obvious in ice thickness and ice volume than in ice area. The see-saw period showed 1 and 2-4 week time-scales.

\section{ACKNOWLEDGEMENTS}

We used AMR data provided by NASDA. SSM/I data were obtained from NSIDC. We thank the Institute of Low Tem- 
perature Science, Hokkaido University, and the Ship Research Institute, Ministry of Transport, and the Japanese Coast Guard for supplying ice-thickness data. We thank D. J. Cavalieri for supplying the tie-points data for the Bering Sea. This study was supported by NASDA through the International Arctic Research Center/NASDA Information System (INIS) research project.

\section{REFERENCES}

Cavalieri, D. J. 1994. A microwave technique for mapping thin sea ice. $\mathcal{F}$ Geophys. Res., 99 (C6), 12,561-12,572.

Cavalieri, D. J., P. Gloersen and W. J. Campbell. 1984. Determination of sea ice parameters with the NIMBUS 7 SMMR. 7. Geophys. Res., 89(D4), 5355-5369.

Cavalieri, D. J. and 6 others. 1991. Aircraft active and passive microwave validation of sea ice concentration from the Defense Meteorological Satellite program special sensor microwave imager. 7. Geophys. Res., 96(C12), 21,989-22,008.

Cho, K., N. Sasaki, H. Shimoda, T. Sakata and F. Nishio. 1996. Evaluation and improvement of SSM/I sea ice concentration algorithms for Sea of Okhotsk. 7. Remote Sensing Soc. Fpn, 16(2), 47-58.

Enomoto, H. 1996. Observation of thin ice area in the Okhotsk Sea and impacts for climatological study. 7. Remote Sensing Soc. Jpn, 16(2), 14-25.

Eppler, D. T. and 14 others. 1992. Passive microwave signatures of sea ice. In Carsey, F. D. and 7 others, eds Microwave remote sensing of sea ice. Washington, DC, American Geophysical Union, 47-71. (Geophysical Monograph Series 68.)

Hollinger, J. P., ed.. 1989. DMSP Special Sensor Microwave/Imager calibration/ validation team final report. Vol. 1. Washington, D.C., U.S. Naval Research Laboratory.
Markus, T. and D. J. Cavalieri. 1998. Snow depth distribution over sea ice in the Southern Ocean from satellite passive microwave data. In Jeffries, M. O., ed. Antarctic sea ice: physical processes, interactions and variability. Washington, DC, American Geophysical Union, 19-39. (Antarctic Research Series 74.)

Nishio, F. and K. Cho. 1996. Sea ice extents in the Okhotsk Sea improvement for sea ice concentration and climatic interpretation. 7. Remote Sensing Soc. Jpn, 16(2), 26-31.

Parkinson, C. L., D. J. Cavalieri, P. Gloersen, H. J. Zwally and J. C. Comiso. 1999. Arctic sea ice extents, areas, and trends, 1978-1996. F. Geophys. Res., 104(C9), 20,837-20,856.

Tachibana, Y., M. Honda and K. Takeuchi. 1996. The abrupt decrease of the sea ice over the southern part of the Sea of Okhotsk in 1989 and its relation to the recent weakening of the Aleutian Low. 7. Meteorol. Soc. Fpn, 74(4), 579-584.

Tateyama, K. and H. Enomoto. 2000. Estimation of the volume of sea ice cover in the Sea of Okhotsk and related atmospheric conditions for 1991/ 92-1998/99 winters. Polar Meteorol. Glaciol. 14, 58-67.

Tateyama, K., H. Enomoto, S. Takahashi, K. Shirasaki, K. Hyakutake and F. Nishio. 2000. New passive microwave remote sensing technique for sea ice in the Sea of Okhotsk using 85-GHz channel of DMSP SSM/I. Bull. Glaciol. Res. 17, 23-30.

Toyota, T., J. Ukita, K. I. Ohshima, M. Wakatsuchi and K. Muramoto. 1999. A measurement of sea ice albedo over the southwestern Okhotsk Sea. 7. Meteorol. Soc. Jpn, 77(1), 117-133.

Troy, B. E., J. P. Hollinger, R. M. Lerner and M. M. Wisler. 1981. Measurement of the microwave properties of sea ice at $90 \mathrm{GHz}$ and lower frequencies. 7 . Geophys. Res., 86(C5), 4283-4289.

Wensnahan, M., G. A. Maykut, T. C. Grenfell and D. P. Winebrenner. 1993. Passive microwave remote sensing of thin sea ice using principal component analysis. 7. Geophys. Res., 98 (C7), 12,453-12,468. 